\title{
Normal reference values for thoracic and abdominal aorta and main pulmonary artery dimensions by cardiovascular magnetic resonance: the Framingham heart study
}

\author{
Michael L Chuang ${ }^{1 *}$, Philimon Gona ${ }^{1}$, Carol J Salton ${ }^{2}$, Connie W Tsao ${ }^{1,2}$, Susan B Yeon ${ }^{2}$, Christopher J O'Donnell ${ }^{1}$, \\ Warren J Manning ${ }^{2}$
}

From 16th Annual SCMR Scientific Sessions

San Francisco, CA, USA. 31 January - 3 February 2013

\section{Background}

Enlargement of the aorta or main pulmonary artery (MPA) is associated with cardiopulmonary disease, and an increased MPA-to-ascending aorta ratio is associated with pulmonary hypertension. We sought to determine mean and upper 90th percentile (p90) diameters of the thoracic and abdominal aorta and MPA in a longitudinally-followed adult cohort without clinical cardiopulmonary disease.

\section{Methods}

1794 Framingham Heart Study Offspring cohort members $(65 \pm 9$ yrs, 844 men) underwent ECG-gated, free breathing T2-weighted black-blood TSE at 1.5T (Philips Gyroscan NT, TR $=3 \mathrm{RR}, \mathrm{TE}=45 \mathrm{~ms}$, trigger delay $=75 \mathrm{~ms}$ (thorax) or $125 \mathrm{~ms}$ (abdomen), 1.03x0.64- $\mathrm{mm}^{2}$ in-plane resolution, $\mathrm{THK}=5 \mathrm{~mm}, \mathrm{Gap}=5$ (abdomen) or $10 \mathrm{~mm}$ (thorax)). Ascending (ASC) and descending thoracic (DTA) aortic and MPA diameters were measured at MPA-bifurcation level, abdominal (ABD) aorta was measured $5 \mathrm{~mm}$ above renal artery origins. We determined sex-specific mean, SD and p90 values for vessel diameters and MPA/ASC ratio in a healthy referent group free of hypertension $(\mathrm{SBP} \geq 140$ or $\mathrm{DBP} \geq 90 \mathrm{mmHg}$ or on medication), obesity (body mass index $\geq 30 \mathrm{~kg} / \mathrm{m}^{2}$ ), emphysema, prevalent myocardial infarction or heart failure, and any smoking history. Men were compared to women using 2-sample $t$ test. We also indexed vessel diameters to sex-and-vessel specific allometric powers of

\footnotetext{
${ }^{1} \mathrm{NHLBI}$ 's Framingham Heart Study, Framingham, MA, USA

Full list of author information is available at the end of the article
}

height $\left(\mathrm{HT}^{\beta}\right)$; $\beta$ 's were determined by linear regression of $\log (\mathrm{HT})$ to $\log$ (diameter). Indexation to $\mathrm{HT}^{\beta}$ was selected since indexation to HT or body surface area (BSA) resulted in significant inverse correlations of vessel diameters to $\mathrm{HT}$ and/or BSA.

\section{Results}

370 Offspring ( $62 \pm 9$ yrs) met referent-group criteria. Men had greater aortic (at all levels) and MPA diameters than women both before and after indexation to $\mathrm{HT}^{\beta}$. The $\beta$ values corresponding to ASC, DTA, ABD and MPA were $0.22,0.30,0.11$ and 0.29 , respectively, in men, and $0.10,0.39,0.37$ and 0.48 in women. Vessel diameters indexed to $\mathrm{HT}^{\beta}$ were correlated with neither HT nor BSA. The MPA/ASC ratio did not differ between sexes. The mean \pm SD and upper limits (p90) for raw and indexed vessel diameters and MPA/ASC ratio are shown (Table).

\section{Conclusions}

We present CMR-derived sex-specific upper 90th percentile values for aortic and MPA diameters and MPA/ASC ratio derived from a cohort of longitudinally-followed, community dwelling adults free of clinical cardiac and pulmonary disease. These p 90 thresholds may be useful for identification of cardiopulmonary pathology.

\section{Funding}

Supported in part by grant RO1 AG17509 and by subcontract N01-HC-38038 from the National Institutes of Health. 
Table 1

\begin{tabular}{ccccc}
\hline & Men & p90 (Men) & Women & p90 (Women) \\
\hline ASC, mm & $31.1 \pm 2.9$ & 34.9 & $28.5 \pm 3.1$ & 31.8 \\
DTA, mm & $23.0 \pm 2.0$ & 25.3 & $20.2 \pm 1.8$ & 22.7 \\
ABD, mm & $17.9 \pm 1.6$ & 20.0 & $15.3 \pm 1.5$ & 17.3 \\
MPA, mm & $23.4 \pm 2.9$ & 26.6 & $21.3 \pm 3.1$ & 24.2 \\
ASC/HT & $27.5 \pm 2.6$ & 30.9 & $27.1 \pm 2.9$ & 30.4 \\
DTA/ $\mathrm{HT}^{\beta}$ & $19.4 \pm 1.7$ & 21.4 & $16.7 \pm 1.5$ & 18.6 \\
ABD/ $\mathrm{HT}^{\beta}$ & $16.8 \pm 1.5$ & 18.9 & $12.8 \pm 1.3$ & 14.4 \\
MPA/ HT & $19.9 \pm 2.5$ & 22.5 & $16.9 \pm 2.4$ & 19.1 \\
MPA/ASC & $0.76 \pm 0.10$ & 0.88 & $0.75 \pm 0.15$ & 0.87 \\
\hline
\end{tabular}

\section{Author details}

${ }^{1} \mathrm{NHLBI}$ 's Framingham Heart Study, Framingham, MA, USA. ${ }^{2}$ Cardiovascular

Division, Beth Israel Deaconess Medical Center, Boston, MA, USA.

Published: 30 January 2013

doi:10.1186/1532-429X-15-S1-P256

Cite this article as: Chuang et al:: Normal reference values for thoracic and abdominal aorta and main pulmonary artery dimensions by cardiovascular magnetic resonance: the Framingham heart study. Journal of Cardiovascular Magnetic Resonance 2013 15(Suppl 1):P256.

Submit your next manuscript to BioMed Central and take full advantage of:

- Convenient online submission

- Thorough peer review

- No space constraints or color figure charges

- Immediate publication on acceptance

- Inclusion in PubMed, CAS, Scopus and Google Scholar

- Research which is freely available for redistribution

Submit your manuscript at www.biomedcentral.com/submit 